Check for updates

Cite this: Nanoscale Adv., 2019, 1, 3918

\title{
Mechanochemically-assisted solvent-free and template-free synthesis of zeolites ZSM-5 and mordenite $\uparrow$
}

\author{
Majid H. Nada, ${ }^{a}$ Sarah C. Larsen (iD *ab and Edward G. Gillan (D)*a
}

Aluminosilicate-based zeolite materials, such as ZSM-5 and mordenite, are well-studied as catalysts. Typical approaches to synthesize these zeolites require either templates or seeds to direct ordered crystal growth and both of these are expensive and add to the complexity of zeolite synthesis. In this paper, we describe a solvent-free and template-free method to synthesize crystalline ZSM-5 and mordenite zeolites without any added seed crystals. Key to the success of this approach is a mechanochemical precursor prereaction step. High-energy ball-milling is used to initiate a solid-state metathesis (exchange) reaction between $\mathrm{Na}_{2} \mathrm{SiO}_{3}$ and $\mathrm{Al}_{2}\left(\mathrm{SO}_{4}\right)_{3}$ reagents, forming crystalline $\mathrm{Na}_{2} \mathrm{SO}_{4}$ and well-mixed aluminosilicate precursor. The solid precursor mixture is thermally converted to crystalline ZSM-5 or mordenite at moderate $180{ }^{\circ} \mathrm{C}$ temperatures without solvents or an organic amine structure directing template. Variations in $\mathrm{Si} / \mathrm{Al}$ ratios in the precursor mixture and additions of solid $\mathrm{NaOH}$ to the mechanochemical reaction were found to influence the subsequent growth of either crystalline ZSM-5 or mordenite zeolites. The crystalline zeolites from this solvent-free and template free method have high $\sim 300 \mathrm{~m}^{2} \mathrm{~g}^{-1}$ surface areas directly from the synthesis without requiring high-temperature calcination. These materials are also comparably active to their commercial counterparts in cellulose and glucose biomass catalytic conversion to hydroxymethylfurfural.

Received 24th June 2019

Accepted 22nd August 2019

DOI: 10.1039/c9na00399a

rsc.li/nanoscale-advances synthesis at relatively high temperatures and pressures for long times $\left(170-230{ }^{\circ} \mathrm{C}\right.$, and $\left.68-120 \mathrm{~h}\right) .^{2,7-11}$ These templated solvothermal syntheses have several drawbacks including environmental waste issues related to the separation and disposal of aqueous solutions containing inorganic and organic species and energy-intensive issues related to subsequent hightemperature air calcination required to destructively remove the organic template form the internal pores of the product zeolite. The internal pore structure of a zeolite must be accessible for desired catalyst or separation activities.

There is ongoing interest in developing zeolite syntheses that are more sustainable and environmentally friendly, such as by eliminating or reducing the amount of required solvents or organic templates. For example, some studies report the aqueous solvothermal organic template-free synthesis of ZSM-5 and mordenite zeolites., ${ }^{1,5,12-20}$ The elimination of structure directing organic templates has been accomplished by judicious manipulation of inorganic components (e.g., Na, Al, Si) in the solution environment to facilitate zeolite nucleation and particle growth. ${ }^{5,18,21-23}$ Alternatively, crystalline zeolite nanoparticles have been used as growth seeds in solvothermal reactions instead of organic molecular templates. In solvothermal ZSM-5 zeolite synthesis, ZSM-5 seeds are added to the precursor solution and growth of the zeolite occurs on the surface of the seeds. ${ }^{24-27}$ We and others have reported the successful seed-assisted synthesis of ZSM-5, ZSM-11, beta, and 
mordenite zeolites. ${ }^{\mathbf{2 4 , 2 6 , 2 8 - 3 1}}$ Some potential drawbacks of seedassisted zeolite syntheses are that reactions still generate mixed inorganic/organic liquid waste and they also require the careful production and characterization of nanoparticle seeds prior to large scale zeolite synthesis.

Water or alcohols are typically used in solvothermal zeolite synthesis to enhance metal ion mixing and diffusion, leading to crystal growth. Solvents are at high temperatures near $200{ }^{\circ} \mathrm{C}$ and may generate high pressures during heating that require use of high pressure reaction vessels. The use and disposal of large amounts of solvent also increases the complexity of zeolite synthesis. To overcome potential solvothermal reaction issues, several studies describe solvent-free zeolite synthesis. ${ }^{\mathbf{3 2 - 4 1}}$ Recently crystalline mordenite zeolite was produced by a solvent-free and template-free reaction at $200{ }^{\circ} \mathrm{C}$ with boehmite aluminum oxyhydroxide, $\mathrm{Na}_{2} \mathrm{SiO}_{3}$, and silicic acid. ${ }^{42}$

Our recent contribution to solvent-free ZSM-5 zeolite synthesis identified mechanochemically induced precursor reactions that enabled the successful synthesis of crystalline ZSM-5. ${ }^{32,43}$ We found that extended manual grinding of $\mathrm{Na}_{2}$ $\mathrm{SiO}_{3} \cdot 9 \mathrm{H}_{2} \mathrm{O}$ with $\mathrm{NH}_{4} \mathrm{Cl}$ produced crystalline $\mathrm{NaCl}$ via a solidstate exchange reaction and created a basic paste from $\mathrm{NH}_{4} \mathrm{OH}$ and freed waters of hydration. The inclusion of $\mathrm{Al}(\mathrm{OH})_{3}$ in the mixture led to well-mixed aluminosilicate reactants. An organic zeolite structure directing agent, tetrabutylammonium bromide (TBABr) was also part of the reagent mixture and was necessary for the successful growth of crystalline ZSM-5 in subsequent $160{ }^{\circ} \mathrm{C}$ solvent-free reactions. Calcination at $550{ }^{\circ} \mathrm{C}$ was required after synthesis to open the zeolite pore structure by removal of the embedded organic template.

Mechanochemical reactions have gained a strong foothold in recent years as a component of the organic and inorganic materials reaction toolbox and there are several examples of their use in synthesizing complex solid-state materials. ${ }^{\mathbf{4 4}}$ For example, one recent study shows that lead-based mixed-halide solid-solution perovskites are produced using mechanochemical reactions between cesium halides and lead halides ${ }^{45}$ and another describes the formation of transition-metal porphyrins without solvent. ${ }^{46}$ The mechanochemical approach relies on the grinding force to destroy the crystalline structure of solid reagents. Small amounts of solvent or water may be added or released from hydrated forms of reagents during the grinding process. These solvent additives can facilitate reactions between starting materials and lead to the formation of intermediates and target materials. ${ }^{32,44,47,48}$

Given the success of mechanochemically assisted solventfree zeolite synthesis, we examined alternate precursor combinations and hydroxide base modifications without organic amine or zeolite seed structure directing templates. This study reports our success with high energy ball milling that provides sufficient mechanochemical energy to achieve a reaction between $\mathrm{Na}_{2} \mathrm{SiO}_{3}$ and $\mathrm{Al}_{2}\left(\mathrm{SO}_{4}\right)_{3}$ and yields crystalline $\mathrm{Na}_{2} \mathrm{SO}_{4}$ and an intimately mixed aluminosilicate precursor. Through alterations in $\mathrm{Si} / \mathrm{Al}$ and $\mathrm{Na} / \mathrm{Al}$ ratios in the precursor mixture, both crystalline ZSM-5 and mordenite zeolites are produced at $180{ }^{\circ} \mathrm{C}$ with high surface areas without requiring a high temperature calcination step. This work represents a rare example of zeolite crystal growth in the absence of solvent, organic structure directing agents, or zeolite seed crystals. These crystalline zeolites function as effective biomass catalysts analogous to their commercial analogs (e.g., glucose to hydroxymethylfurfural conversion).

\section{Experimental section}

\section{Materials}

All reagents were used as received: sodium silicate $\mathrm{Na}_{2} \mathrm{SiO}_{3}$ . $9 \mathrm{H}_{2} \mathrm{O}$ (98\%, Acros), silica gel $\mathrm{SiO}_{2}$ (Sigma-Aldrich), aluminum sulfate $\mathrm{Al}_{2}\left(\mathrm{SO}_{4}\right)_{3} \cdot x \mathrm{H}_{2} \mathrm{O}$ ( $x=14-18,98 \%$ Sigma-Aldrich), $\mathrm{NaOH}$ (99.8\%, Fisher Scientific), microcrystalline cellulose (99\%, Sigma-Aldrich), glucose (97\%, Sigma-Aldrich), and hydroxymethylfurfural (HMF, 99\%, Sigma-Aldrich). Commercial ZSM5 (sodium and acid-exchanged forms) and mordenite (sodium form) zeolite standards were obtained from Zeolyst.

\section{Mechanochemically-assisted zeolite synthesis: grinding and heating time effects}

A solid zeolite precursor mixture was prepared using the following mole ratio of $\mathrm{Na}_{2} \mathrm{SiO}_{3} \cdot 9 \mathrm{H}_{2} \mathrm{O}$ (5.03 mmol), $\mathrm{SiO}_{2}$ (24 $\mathrm{mmol})$, and $\mathrm{Al}_{2}\left(\mathrm{SO}_{4}\right)_{3} \cdot 18 \mathrm{H}_{2} \mathrm{O}(0.98 \mathrm{mmol})$. The solid mixture was ground for 25 and $50 \mathrm{~min}$ at $1400 \mathrm{rpm}$ by the high energy ball mill grinder (Form-Tech Scientific FTS 1000 with $30 \mathrm{~mL}$ Teflon jars and two $10 \mathrm{~mm} \mathrm{ZrO}_{2}$ grinding balls). After the grinding, the fine powder mixture was transferred to a $30 \mathrm{~mL}$ Teflon lined steel Parr autoclave and heated in a box oven at $180{ }^{\circ} \mathrm{C}$ for $24 \mathrm{~h}, 48 \mathrm{~h}$, or $72 \mathrm{~h}$. Comparison experiments were done using physically mixed precursor mixtures without ball mill grinding. The isolated product was washed with water to remove byproduct salts and dried at $80{ }^{\circ} \mathrm{C}$ in air. Typical isolated mass yields based on the amount of $\mathrm{SiO}_{2}$ used are at or above $80 \%$.

\section{Mechanochemically-assisted zeolite synthesis: $\mathrm{Na}, \mathrm{Si}$, and $\mathrm{Al}$ content effects}

Several solid precursor mixtures were prepared with varying mole ratios of $\mathrm{Na}, \mathrm{Si}$, and $\mathrm{Al}$ within these reagent ranges: $\mathrm{Na}_{2}-$ $\mathrm{SiO}_{3} \cdot 9 \mathrm{H}_{2} \mathrm{O}$ (3.0-9.0 mmol), $\mathrm{SiO}_{2}(20-37 \mathrm{mmol})$, and $\mathrm{Al}_{2}\left(\mathrm{SO}_{4}\right)_{3}$ $\cdot 18 \mathrm{H}_{2} \mathrm{O}(0.98 \mathrm{mmol})$ (Table $\left.\mathrm{S} 1 \dagger\right)$. Based on the successful conditions determined from the initial studies above, these solid mixtures were ground by high energy ball milling for $50 \mathrm{~min}$ at $1400 \mathrm{rpm}$, then heated at $180{ }^{\circ} \mathrm{C}$ for $48 \mathrm{~h}$ in an autoclave, followed by water washing and drying at $80{ }^{\circ} \mathrm{C}$. Selected zeolite products were heated to higher temperatures $\left(550{ }^{\circ} \mathrm{C}, 6 \mathrm{~h}\right)$ to examine the thermal stability of their porous crystalline structures.

\section{Mechanochemically-assisted zeolite synthesis: $\mathrm{NaOH}$ additive effects}

Solid precursor mixtures were prepared with varying mole ratios of $\mathrm{Na}, \mathrm{Si}$, and $\mathrm{Al}$ within these reagent ranges: $\mathrm{Na}_{2} \mathrm{SiO}_{3} \cdot 9 \mathrm{H}_{2} \mathrm{O}$ (1.7-7.5 mmol), $\mathrm{NaOH}(2.5 \mathrm{mmol}), \mathrm{SiO}_{2}(20-37 \mathrm{mmol})$, and $\mathrm{Al}_{2}\left(\mathrm{SO}_{4}\right)_{3} \cdot 18 \mathrm{H}_{2} \mathrm{O}(0.98 \mathrm{mmol})$ (Table $\left.\mathrm{S} 1 \dagger\right)$. The addition of a strong $\mathrm{NaOH}$ base provides a second source of sodium ions 
and can aid in solubilizing individual reagents. These solid mixtures were ground by high energy ball milling for $50 \mathrm{~min}$ at $1400 \mathrm{rpm}$, then heated at $180{ }^{\circ} \mathrm{C}$ for $48 \mathrm{~h}$ in an autoclave, followed by water washing and drying at $80{ }^{\circ} \mathrm{C}$.

The text, tables, and figure captions, generally report reagent ratios using conventional zeolite synthesis ratios, namely calculating ideal amounts of $\mathrm{SiO}_{2}, \mathrm{Al}_{2} \mathrm{O}_{3}$, and $\mathrm{Na}_{2} \mathrm{O}$ that could be produced by the precursor mixture. The calculated amount of $\mathrm{SiO}_{2}$ arises from both fumed $\mathrm{SiO}_{2}$ and $\mathrm{Na}_{2} \mathrm{SiO}_{3}, \mathrm{Al}_{2} \mathrm{O}_{3}$ arises from $\mathrm{Al}_{2}\left(\mathrm{SO}_{4}\right)_{3}$, and $\mathrm{Na}$ is calculated as $\mathrm{Na}_{2} \mathrm{O}$ from both $\mathrm{Na}_{2} \mathrm{SiO}_{3}$ and $\mathrm{NaOH}$ (if applicable). In some cases, a value of "free" $\mathrm{Na}_{2} \mathrm{O}$ is calculated assuming that $\mathrm{Na}$ that forms $\mathrm{Na}_{2} \mathrm{SO}_{4}$ is unavailable for zeolite synthesis.

\section{Safety considerations}

In high energy ball milling reactions, reactive precursors may exothermically react in ways that could lead to high heat and/or gas release. While no such incidents were observed in this study, any new energy ball milling reactions should be conducted in small quantities. Sealed autoclaves should be used with care to ensure reactions do not exceed the maximum allowable pressures during heating.

\section{Characterization}

The reagent and product materials were characterized by using a Bruker D-8 DaVinci X-ray diffractometer with $\mathrm{Cu} \mathrm{K} \alpha$ radiation and a 0.04 step size to collect the XRD patterns. XRD data on washed zeolite products was used to estimate the relative crystallinity (RC) of the samples by integrating the peaks between $22.5-25^{\circ} 2 \theta$ with comparison to a commercially available fully crystalline commercial Zeolyst standard. ${ }^{24}$ In order to use XRD intensity measurements for relative crystallinity, identical amounts of each sample and the commercial reference were loaded in a similar way in the XRD sample holder and analyzed under the same instrumental conditions. BET surface area analysis was performed using nitrogen adsorption analysis on a Quantachrome Nova 1200 instrument. Approximately $100 \mathrm{mg}$ of each material was degassed overnight at $300{ }^{\circ} \mathrm{C}$ under vacuum prior to analysis. Surface area analysis was performed using nitrogen gas as the adsorbate and seven-point BET isotherm analysis was used to calculate surface areas. Selected sodium form and acid-exchanged samples were examined by full adsorption-desorption isotherms. The surface acid properties of several acid-exchanged zeolites were studied by pyridine reaction at $100{ }^{\circ} \mathrm{C}$, see details in ESI. $\dagger$ Scanning electron microscopy (SEM) images were collected by using a Hitachi S4800 scanning electron microscope. The samples were affixed to aluminum stubs and sputter coated with a thin layer of conductive metal (mix of gold and platinum). Elemental analysis to determine $\mathrm{Si} / \mathrm{Al} / \mathrm{Na}$ contents for select washed zeolite products was performed using inductively coupled plasma optical emission spectroscopy (ICP-OES, Varian 720-OES). Samples were prepared by placing $10 \mathrm{mg}$ of zeolite powder in a graduated plastic tube followed by addition of $1.6 \mathrm{~mL}$ of a $70: 30 \mathrm{HCl}: \mathrm{HF}$ solution. The obtained suspension was sonicated for $10 \mathrm{~min}$ and after that, $6 \mathrm{~mL}$ of $5 \mathrm{vol} \%$ boric acid and $0.6 \mathrm{~mL}$ of concentrated nitric acid were added to complete dissolution. DI water was added to adjust the total volume to be $10 \mathrm{~mL}$.

\section{Catalytic evaluation and analysis}

Selected crystalline zeolite products were evaluated for the catalytic hydrolysis of cellulose and glucose into hydroxymethylfurfural (HMF) following similar reported procedures for zeolite biomass catalysis. ${ }^{49}$ First, the acidic $\mathrm{H}$-form of the synthesized zeolite materials and commercial ZSM-5 and mordenite zeolite was obtained by ion exchange with $1 \mathrm{M}$ ammonium nitrate (10 $\mathrm{mL} \mathrm{g}^{-1}$ of zeolite product overnight) followed by heating at $550{ }^{\circ} \mathrm{C}$ for $6 \mathrm{~h}$. Cellulose was ground for $2 \mathrm{~h}$ using high energy ball milling (30 mL Teflon jars and two $10 \mathrm{~mm} \mathrm{ZrO}_{2}$ grinding balls at $1400 \mathrm{rpm}$ ) to improve dispersion. The biomass sample ( $0.125 \mathrm{~g}$ of cellulose or glucose) was dispersed in $5 \mathrm{~mL}$ of DI water and $0.125 \mathrm{~g}$ of the synthesized zeolite (ZSM-5 or mordenite) was then added. This biomass-zeolite mixture was transferred to a $30 \mathrm{~mL}$ Teflon-lined steel autoclave and heated at $190{ }^{\circ} \mathrm{C}$ for $5 \mathrm{~h}$. The post-reaction solid mass remaining contains both unreacted biomass and zeolite catalyst and was separated from the aqueous phase. The separated mass was dried in the oven at $80{ }^{\circ} \mathrm{C}$, and the separated liquid was analyzed by HPLC (Agilent 1100 series equipped with C18 column - Phenomenex Luna $5 \mu$ with dimensions of $4.6 \mathrm{~mm} \times 250 \mathrm{~mm}$, and DAD (UV/ Vis) detector). The mobile phase was $50: 50 \mathrm{v} / \mathrm{v}$ acetonitrile : -

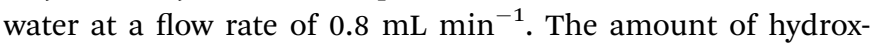
ymethylfurfural (HMF) present in the products was determined by an external standard curve based on the peak area of the HMF signal in the product versus standard solutions. The unreacted biomass was determined as isolated post-reaction solid mass minus the catalyst mass. The percent biomass conversion was calculated as the mass ratio of reacted biomass to initial biomass in the reactor. The yield of HMF was calculated as the ratio of HMF in the solution relative to the amount of initial biomass in the reactor.

\section{Results and discussion}

\section{Mechanochemical pre-reactions for zeolite synthesis using $\mathbf{A l}_{2}\left(\mathbf{S O}_{4}\right)_{3}$}

In our previous work, a crystalline $\mathrm{NaCl}$ byproduct salt formed during a reagent grinding step before heating. Salt formation arises from an important precursor pre-reaction that also sufficiently mixed $\mathrm{Al}$ and $\mathrm{Si}$ components in the solid reagent mixture to yield crystalline ZSM-5 upon heating. ${ }^{32}$ The grinding induced metathesis (exchange) reaction is influenced by the stability of $\mathrm{NaCl}\left(\Delta H_{\mathrm{f}}=-411 \mathrm{~kJ} \mathrm{~mol}^{-1}\right)$ and so other sodium salts, such as $\mathrm{Na}_{2} \mathrm{SO}_{4}\left(\Delta H_{\mathrm{f}}=-1388 \mathrm{~kJ} \mathrm{~mol}^{-1}\right)$, may show similarly useful mechanochemically induced pre-reactions. We found that manual hand grinding provides insufficient mechanical energy to produce $\mathrm{Na}_{2} \mathrm{SO}_{4}$ from $\mathrm{Na}_{2} \mathrm{SiO}_{3}$ and $\mathrm{Al}_{2}\left(\mathrm{SO}_{4}\right)_{3}$. Since $\mathrm{Al}_{2}\left(\mathrm{SO}_{4}\right)_{3}$ is an inexpensive and popular aluminum source reagent in solvothermal zeolite synthesis, we examined high energy ball-milling to mechanochemically facilitate salt formation and reagent pre-reaction and followed 
structural changes in the precursors using powder X-ray diffraction (XRD). Fig. 1A shows the XRD data for mixed reagents and highlights bulk structural changes that occur after 25 and 50 min of high energy ball milling. XRD peaks for both $\mathrm{Na}_{2} \mathrm{SiO}_{3}$ and $\mathrm{Al}_{2}\left(\mathrm{SO}_{4}\right)_{3}$ are present in the unground sample (XRDs of starting materials are shown in Fig. S1 $\dagger$ ). After 25 min of ball-mill grinding, the crystalline reagent peaks disappear or are significantly reduced in intensity and after another $25 \mathrm{~min}$ of grinding there is clear presence of crystalline $\mathrm{Na}_{2} \mathrm{SO}_{4}$ with loss of all reagent XRD peaks. The broad amorphous background present in the 25 and 50 min of milling XRD patterns indicates that the $\mathrm{Na} / \mathrm{Al} / \mathrm{Si}$ components are in a disordered and presumably well-mixed aluminosilicate environment. While $\mathrm{Na}_{2} \mathrm{SO}_{4}$ salt formation may lead to intimate mixing of the $\mathrm{Al}$ and $\mathrm{Si}$ reagents, salt formation can also act to limit subsequent metal oxide particle growth. For example, salt formation via precursor metathesis reactions in a confined aerosol droplet enables nanoparticle oxide growth in the absence of solvents, ${ }^{50}$ and solid-state metathesis reactions with salt inclusion such as $\mathrm{NaCl}$ or $\mathrm{K}_{2} \mathrm{SO}_{4}$ can produce small particles and unusual interconnected porous solids. ${ }^{51,52}$

Based on the high energy ball milling XRD results, $50 \mathrm{~min}$ of grinding likely results in a net mechanochemical pre-reaction consistent with that shown below in eqn (1).

$$
\begin{aligned}
3 \mathrm{Na}_{2} \mathrm{SiO}_{3} \cdot 9 \mathrm{H}_{2} \mathrm{O}+\mathrm{Al}_{2}\left(\mathrm{SO}_{4}\right)_{3} \cdot 18 \mathrm{H}_{2} \mathrm{O} \rightarrow \\
3 \mathrm{Na}_{2} \mathrm{SO}_{4}+{ }^{-} \mathrm{Al}_{2}\left[\mathrm{SiO}_{3}\right]_{3} "+45 \mathrm{H}_{2} \mathrm{O}
\end{aligned}
$$

In our previous work, the reagent's waters of hydration were freed during mechanochemically induced $\mathrm{NaCl}$ formation. ${ }^{32,43}$ Since $\mathrm{NaCl}$ does not form extensive salt hydrates, the released water led to a distinct wet paste-like appearance for the ground precursor mixture. In contrast, the $50 \mathrm{~min}$ ground product from eqn (1) is still a free flowing powder, which is not surprising as $\mathrm{Na}_{2} \mathrm{SO}_{4}$ is a well-known drying agent with extensive hydration ability forming a stable decahydrate, which would tie up most of the reagent freed waters of hydration. In addition to the two reagents in eqn (1), fumed silica is used to produce specific $\mathrm{Si} / \mathrm{Al}$ ratios that are used for zeolite growth. In addition, free sodium ions are needed for zeolite growth and these are supplied by additional $\mathrm{Na}_{2} \mathrm{SiO}_{3}$ and/or, as will be discussed later, through $\mathrm{NaOH}$ additions. In zeolite structures where $\mathrm{Si}^{4+}$ sites are replaced by $\mathrm{Al}^{3+}$, the addition of $\mathrm{Na}^{+}$cations is also needed for charge balance.

While the 50 min high energy ball milling resulted in the most "complete" mechanochemical exchange reactions (Fig. 1A), and effective mixing of solid reagents, this may not necessarily lead to the successful solvent-free and organic template free thermal conversion to crystalline zeolites. Parallel

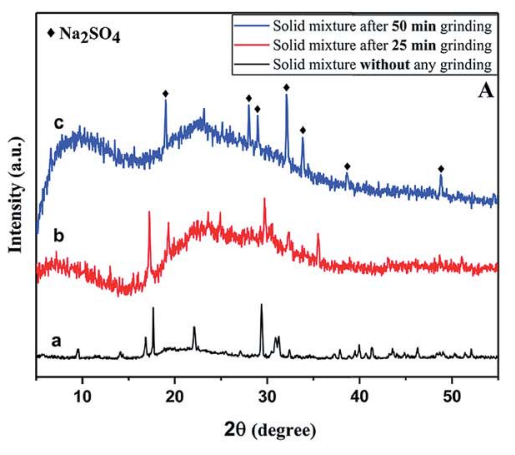

\section{Heating at $180^{\circ} \mathrm{C}$}

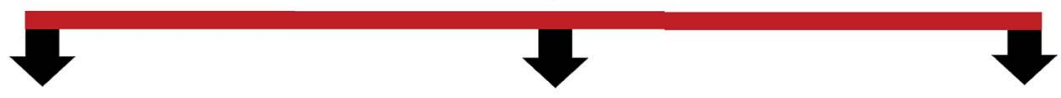

$24 \mathrm{~h}$

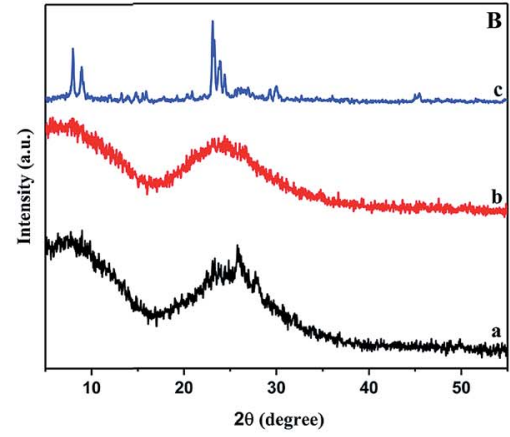

$48 \mathrm{~h}$

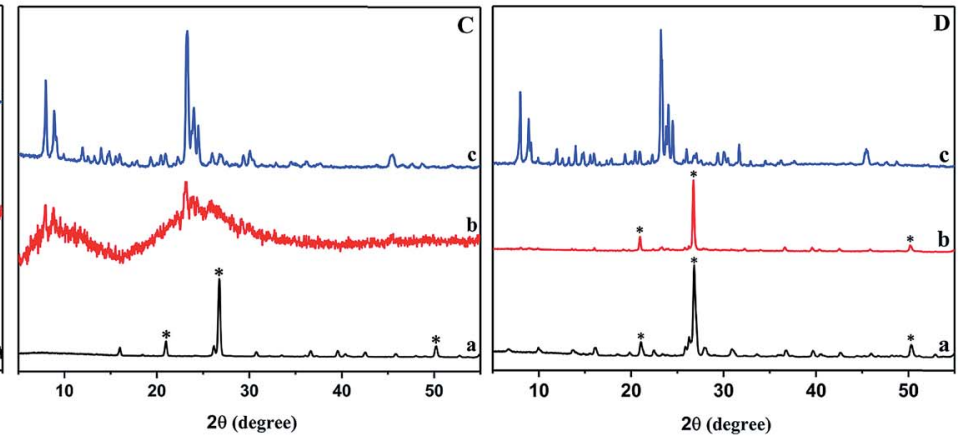

Fig. 1 (A) XRD of solid precursor mixture reagent mixture of $\mathrm{Na}_{2} \mathrm{SiO}_{3}, \mathrm{Al}_{2}\left(\mathrm{SO}_{4}\right)_{3}$, and $\mathrm{SiO}_{2}$ (equivalent $\mathrm{Na}_{2} \mathrm{O}: \mathrm{Al}_{2} \mathrm{O}_{3}: \mathrm{SiO}_{2}$ ratio of $5: 1: 30$ ) ground for different periods of time ( $a=$ no grinding, $b=25 \mathrm{~min}$, and $c=50 \mathrm{~min}$ ). Asterisks in A indicate $\mathrm{Na}_{2} \mathrm{SO}_{4}$. The XRD of washed products after heating at $180^{\circ} \mathrm{C}$ for periods of: $24 \mathrm{~h} \mathrm{(B),} 48 \mathrm{~h}$ (C), and $72 \mathrm{~h}$ (D). Asterisks in (C) and (D) indicate quartz peaks. 
solvent-free zeolite synthesis reactions were performed at $180{ }^{\circ} \mathrm{C}$ with solid precursor mixtures that were unground and subjected to $25 \mathrm{~min}$ or $50 \mathrm{~min}$ of high energy ball mill grinding. The $180{ }^{\circ} \mathrm{C}$ heating time was varied from 24 to $72 \mathrm{~h}$ and the isolated products after heating were washed with water to remove byproduct salts and soluble species. The XRD results from $24 \mathrm{~h}$ heating at $180^{\circ} \mathrm{C}$ (Fig. 1B) clearly show that crystalline ZSM-5 is only produced from the 50 min ball milled reagent mixture. All of the crystalline peaks in Fig. $1 \mathrm{~B}(\mathrm{c})$ correspond to ZSM-5 (PDF \#00-037-0361), while the XRD patterns of both unground and $25 \mathrm{~min}$ ball milled samples are essentially amorphous. The relative crystallinity of the $24 \mathrm{~h}(50 \mathrm{~min}$ ball milling) product was about $68 \%$ and with a measured surface area of $198 \mathrm{~m}^{2} \mathrm{~g}^{-1}$. These values indicate that the ZSM-5 product after $24 \mathrm{~h}$ heating is not fully crystallized. Extended heating of the 50 min ball milled reagent mixture for 48 and $72 \mathrm{~h}$ results in improved crystallinity for ZSM-5 (Fig. 1C and D). The $48 \mathrm{~h}$ and $72 \mathrm{~h}$ ZSM- 5 reaction products have relative crystallinities (surface areas) of $95 \%\left(324 \mathrm{~m}^{2} \mathrm{~g}^{-1}\right)$ and $93 \%\left(311 \mathrm{~m}^{2}\right.$ $\mathrm{g}^{-1}$ ), respectively. In contrast, the unground and $25 \mathrm{~min}$ ball milled mixture transform from amorphous materials to dense crystalline quartz rather than to porous aluminosilicate zeolites. These results indicate that the extended $50 \mathrm{~min}$ ball-milling prereaction that forms crystalline $\mathrm{Na}_{2} \mathrm{SO}_{4}$ also produces sufficiently mixed aluminosilicate intermediates that yield crystalline porous zeolite framework structures. Zeolite growth and crystallization at $180^{\circ} \mathrm{C}$ takes place in the presence of a $\mathrm{Na}_{2} \mathrm{SO}_{4}$ salt that will release its waters of hydration during the reaction and they may influence zeolite crystallization and particle growth. This is a rare example of crystalline zeolite synthesis without any added solvent or organic molecular or zeolite seed structure directing templates.

The SEM images of the crystalline ZSM-5 products from $50 \mathrm{~min}$ ball milled mixtures also show a progression from irregular and incompletely formed particles after $24 \mathrm{~h}$ of heating to faceted $\sim 8 \mu \mathrm{m}$ aggregated crystallites after $48 \mathrm{~h}$ and finally to fairly uniform $\sim 13 \mu \mathrm{m}$ particles after $72 \mathrm{~h}$ of heating at $180^{\circ} \mathrm{C}$ (Fig. 2). These microscopy results show that even in the absence of solvent or hydrothermal gel to crystallite transformations, the mechanochemically mixed reagents are sufficiently combined to grow into large organized faceted particles in the ten micrometer range.

In conventional zeolite synthesis, an organoamine structure directing template fills the zeolite pores and is removed by a high temperature air calcination step that then yields zeolites with high surface area. Since our reactions do not contain organic templates, a higher temperature air calcination is not required to access the internal zeolite pore structure. To examine the structural stability of our $180{ }^{\circ} \mathrm{C}$ synthesized materials, products from a $50 \mathrm{~min}$ ball mill pre-reaction followed by $180^{\circ} \mathrm{C}$ heating for 24,48 , or $72 \mathrm{~h}$ were subsequently calcined at higher $550{ }^{\circ} \mathrm{C}$ temperatures in air. The XRD patterns for the calcined samples are shown in Fig. S2. $\dagger$ The sample from a $24 \mathrm{~h}$ synthesis was unstable and collapsed to a dense quartz phase after the calcination. On the other hand, samples from longer synthesis times ( 48 and $72 \mathrm{~h}$ ) retained stable crystalline the ZSM-5 zeolite structure after calcination
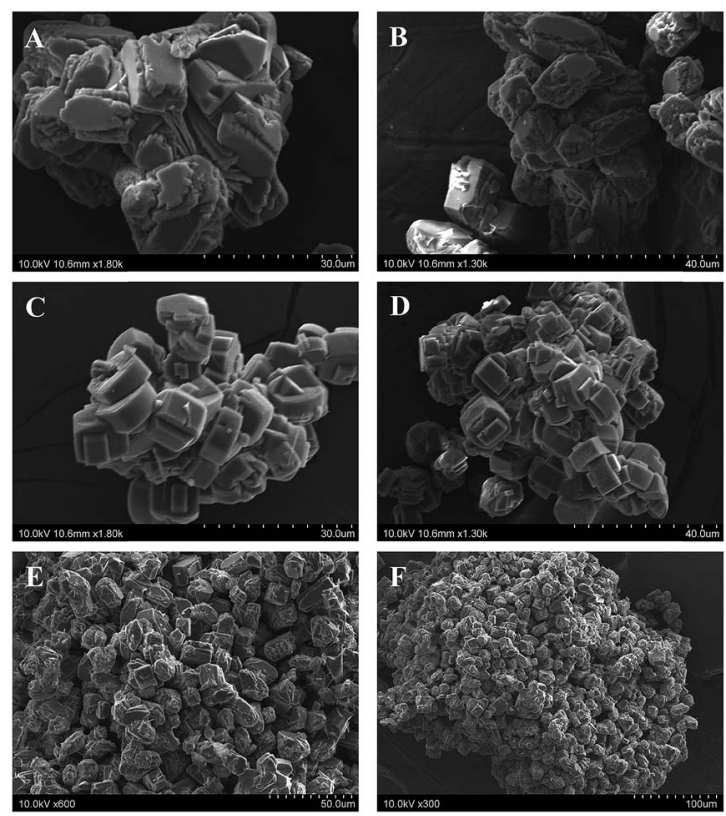

Fig. 2 SEM images for crystalline washed ZSM-5 zeolites synthesized from a reagent mixture of $\mathrm{Na}_{2} \mathrm{SiO}_{3}, \mathrm{Al}_{2}\left(\mathrm{SO}_{4}\right)_{3}$, and $\mathrm{SiO}_{2}$ (equivalent $\mathrm{Na}_{2} \mathrm{O}: \mathrm{Al}_{2} \mathrm{O}_{3}: \mathrm{SiO}_{2}$ ratio of $5: 1: 30$ ) that was subjected to 50 minutes of mechanochemical ball mill grinding and then thermally treated at $180^{\circ} \mathrm{C}$ for $24 \mathrm{~h} \mathrm{(A}$ and $\left.\mathrm{B}\right), 48 \mathrm{~h}$ (C and D), and $72 \mathrm{~h}$ (E and F).

(Fig. S2 $\dagger$ ). These results are consistent with our recent work on a different mechanochemical ZSM-5 reaction where incomplete initial structure formation led to decomposition to dense silica after calcination. ${ }^{43}$

\section{Influence of sodium and silica content on mechanochemically-assisted zeolite synthesis}

High energy ball milling provides sufficient energy to cause significant chemical exchange reactions between the silicate and sulfate reagents, leading to salt formation and producing a well-mixed aluminosilicate mixture with all of the required nutrients to form zeolite crystals. The growth of crystalline micrometer-sized zeolite crystals in the absence of both solvent and an organoamine molecular template may proceed via $\mathrm{Na}^{+}$ facilitated templating. Sodium cations have been proposed to serve as inorganic structure directing agents in solvothermal zeolite syntheses that do not use an organic template. . $^{13,18,21-23,53}$ In order to examine the role of excess sodium ions in this mechanochemically assisted synthesis of crystalline ZSM-5 without solvent or organic template, we modified the amount of excess $\mathrm{Na}$ available after $\mathrm{Na}_{2} \mathrm{SO}_{4}$ formation using varying amounts of $\mathrm{Na}_{2} \mathrm{SiO}_{3}$ or adding solid $\mathrm{NaOH}$. In the latter case, $\mathrm{NaOH}$ is expected to also modify the local basicity of the ground mixture to further facilitate $\mathrm{M}-\mathrm{OH}$ formation and condensation. Given that different crystalline zeolite structures can form as ratios of Si/Al vary in a reaction mixture, we examined these mechanochemically-assisted solvent free zeolite reactions with $\mathrm{SiO}_{2} / \mathrm{Al}_{2} \mathrm{O}_{3}$ ratios of 30 and $40 .{ }^{53}$

Sodium cations $\left(\mathrm{Na}^{+}\right)$have a charge balancing function for $\mathrm{Al}^{3+}$ substitution into silica-based zeolites. They also can play 
a role as a structure-directing agent to facilitate the growth of crystalline zeolites in the absence of an organic template directing agent. ${ }^{22,23}$ In our synthesis, $\mathrm{Na}_{2} \mathrm{SiO}_{3}$ is the sodium source and after grinding some sodium will be sequestered as $\mathrm{Na}_{2} \mathrm{SO}_{4}$. Several reagent mixtures with varying $\mathrm{Na}_{2} \mathrm{SiO}_{3}$ amounts were ball-milled for $50 \mathrm{~min}$ followed by $180^{\circ} \mathrm{C}$ heating for $48 \mathrm{~h}$ to determine the influence of sodium content in the reagent mixture on the crystallinity of the zeolite product. The $\mathrm{Na}_{2} \mathrm{SiO}_{3}$, $\mathrm{Al}_{2}\left(\mathrm{SO}_{4}\right)_{3}$, and $\mathrm{SiO}_{2}$ precursor mixtures corresponded to equivalent $\mathrm{Na}_{2} \mathrm{O}: \mathrm{Al}_{2} \mathrm{O}_{3}: \mathrm{SiO}_{2}$ ratio of $x: 1: 30$, where $x$ was varied from 3-9. Notice from eqn (1), that when $x=3$, this corresponds to essentially all $\mathrm{Na}^{+}$from $\mathrm{Na}_{2} \mathrm{SiO}_{3}$ being sequestered in the three $\mathrm{Na}_{2} \mathrm{SO}_{4}$ byproducts during the mechanochemical prereaction, thus there may be no "free" $\mathrm{Na}^{+}$available for subsequent zeolite structure directing/templating. After thermal treatment, the $x=3$ reaction resulted in an amorphous XRD pattern, but as the "free" sodium ion content increased, the growth of crystalline ZSM-5 is evident (Fig. 3). At the highest levels of excess sodium examined here $\left(\mathrm{Na}_{2} \mathrm{O} / \mathrm{Al}_{2} \mathrm{O}_{3}=9\right)$, a more aluminum-rich mordenite zeolite (PDF \#00-011-0155) is crystallized instead of ZSM-5. Poorly crystalline ZSM-5 and mordenite are observed with a $\mathrm{Na}_{2} \mathrm{O} / \mathrm{Al}_{2} \mathrm{O}_{3}=7$ reaction ratio. The growth of some crystalline ZSM-5 is evident even at low "free" sodium levels $\left(\mathrm{Na}_{2} \mathrm{O} / \mathrm{Al}_{2} \mathrm{O}_{3}=4\right)$ showing the value of welldistributed sodium cations present in the ball-milled and exchanged precursor mixture that allows zeolite structure direction from low sodium content in the absence of solvent or organic template.

A different approach to modify the sodium content in the precursor mixture was accomplished through the addition of solid $\mathrm{NaOH}$ to the reagent mixture consisting of $\mathrm{Na}_{2} \mathrm{SiO}_{3}, \mathrm{SiO}_{2}$, and $\mathrm{Al}_{2}\left(\mathrm{SO}_{4}\right)_{3}$. In addition to providing a source of sodium, $\mathrm{NaOH}$ addition significantly alters the basicity of the resulting solid mixture, which can aid in metal hydroxide formation and

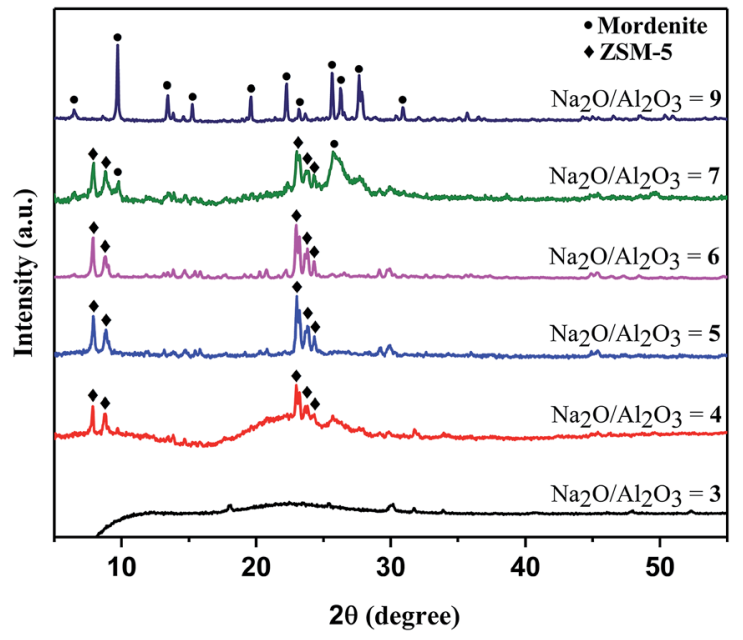

Fig. 3 XRD of samples synthesized from a reagent mixture of $\mathrm{Na}_{2} \mathrm{SiO}_{3}$, $\mathrm{Al}_{2}\left(\mathrm{SO}_{4}\right)_{3}$, and $\mathrm{SiO}_{2}$ (equivalent $\mathrm{Na}_{2} \mathrm{O}: \mathrm{Al}_{2} \mathrm{O}_{3}: \mathrm{SiO}_{2}$ ratio of $x: 1: 30$, where $x=3-9$ ) that was mechanochemically ground for $50 \mathrm{~min}$, then thermally treated at $180{ }^{\circ} \mathrm{C}$ for $48 \mathrm{~h}$, and then washed with water. Peaks for $\mathrm{Na}_{2} \mathrm{O} / \mathrm{Al}_{2} \mathrm{O}_{3}$ of 5 and 6 correspond to $\mathrm{ZSM}-5$ zeolite and at a ratio of $9, \mathrm{XRD}$ peaks correspond to mordenite zeolite. condensation. The reagents were ball-milled for $50 \mathrm{~min}$ with varying amounts of $\mathrm{NaOH}$ to maintain the same $\mathrm{Na} / \mathrm{Al} / \mathrm{Si}$ ratios as used above (equivalent $\mathrm{Na}_{2} \mathrm{O}: \mathrm{Al}_{2} \mathrm{O}_{3}: \mathrm{SiO}_{2}$ ratio of $x: 1: 30$, where $x=3-9$ ). After $180{ }^{\circ} \mathrm{C}$ heating for $48 \mathrm{~h}$, the washed products showed the XRD patterns in Fig. 4. One clear effect of $\mathrm{NaOH}$-based sodium ion addition on basicity or reactivity is that the more aluminum-rich mordenite zeolite preferentially crystallizes over the ZSM-5 zeolite even for the same ratios (e.g., $\mathrm{Na}_{2} \mathrm{O}: \mathrm{Al}_{2} \mathrm{O}_{3}: \mathrm{SiO}_{2}$ ratio of $5: 1: 30$ ) that produced ZSM-5 as shown earlier (Fig. 3).

Given that a more aluminum-rich zeolite, mordenite, crystallizes in preference to ZSM-5 under several conditions of excess sodium ions where the $\mathrm{Al}_{2} \mathrm{O}_{3}: \mathrm{SiO}_{2}$ ratio was fixed at $1: 30$, a series of analogous mechanochemically mixed reactions were performed $\left(180{ }^{\circ} \mathrm{C}, 48 \mathrm{~h}\right)$ using a higher silica ratio equivalent $\left(\mathrm{Al}_{2} \mathrm{O}_{3}: \mathrm{SiO}_{2}\right.$ of $\left.1: 40\right)$ with fumed $\mathrm{SiO}_{2}$ added to increase the silica content. The XRD results of washed products are shown in Fig. S3 and S4. $\dagger$ Generally, without $\mathrm{NaOH}$, the higher silica content yields essentially amorphous products until crystallization of a mixed ZSM-5/mordenite zeolite product at the highest sodium level (equivalent $\mathrm{Na}_{2} \mathrm{O}: \mathrm{Al}_{2}$ $\mathrm{O}_{3}: \mathrm{SiO}_{2}$ ratio of $9: 1: 40$ ). When $\mathrm{NaOH}$ was used to modify the sodium content and basicity of the mechanochemically ground solid mixture of $\mathrm{Na}_{2} \mathrm{SiO}_{3}, \mathrm{Al}_{2}\left(\mathrm{SO}_{4}\right)_{3}$, and $\mathrm{SiO}_{2}$, crystalline ZSM-5 forms at several higher sodium ratios (equivalent $\mathrm{Na}_{2} \mathrm{O}: \mathrm{Al}_{2} \mathrm{O}_{3}: \mathrm{SiO}_{2}$ ratio of $7 / 8: 1: 40$ ), while crystalline mordenite was not observed. Table 1 summarizes the XRD results observed for variations in reagents with and without addition of $\mathrm{NaOH}$.

The solvent-free and organic template free reactions that successfully use high energy ball milling pre-reactions to produce single-phase ZSM-5 or mordenite zeolites are highlighted in bold in Table 1. Zeolite product phase formation was

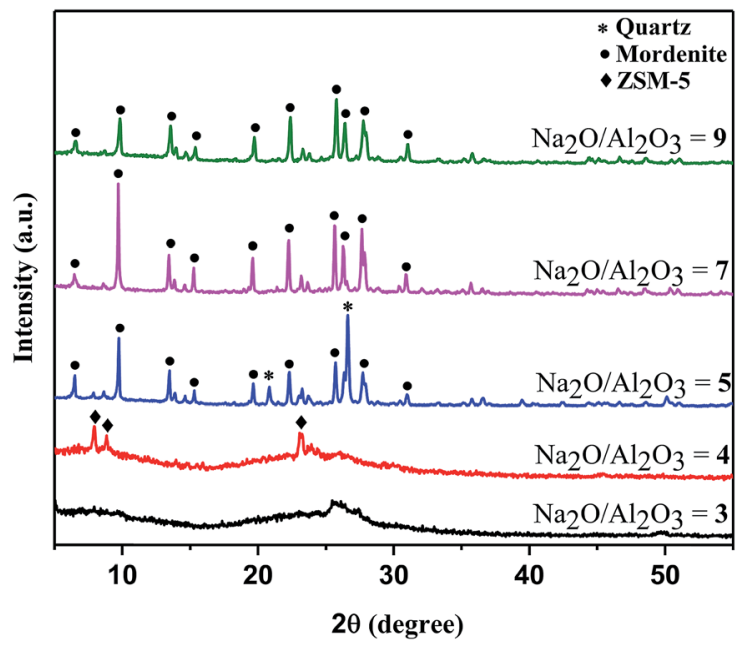

Fig. 4 XRD of samples synthesized from a reagent mixture of $\mathrm{NaOH}$, $\mathrm{Na}_{2} \mathrm{SiO}_{3}, \mathrm{Al}_{2}\left(\mathrm{SO}_{4}\right)_{3}$, and $\mathrm{SiO}_{2}\left(\mathrm{Na}_{2} \mathrm{O}: \mathrm{Al}_{2} \mathrm{O}_{3}: \mathrm{SiO}_{2}\right.$ ratio of $x: 1: 30$, where $x=3-9$ ) that was mechanochemically ground for $50 \mathrm{~min}$, then thermally treated at $180{ }^{\circ} \mathrm{C}$ for $48 \mathrm{~h}$, and then washed with water. Peaks for $\mathrm{Na}_{2} \mathrm{O} / \mathrm{Al}_{2} \mathrm{O}_{3}$ ratio of 7 and 9 correspond to mordenite, at a ratio of 5 mordenite also contains weak quartz peaks near 22 and $27^{\circ}$, and at ratio of 4 , weak ZSM-5 is present. 
Table 1 Summary of powder XRD results for zeolites synthesized from mechanochemically reacted precursor mixtures $\mathrm{Na}_{2} \mathrm{SiO}_{3}, \mathrm{Al}_{2}\left(\mathrm{SO}_{4}\right)_{3}$, and $\mathrm{SiO}_{2}$ (with or without added $\mathrm{NaOH}$ ) that were equivalent mixtures of metal oxide with $\mathrm{Na}_{2} \mathrm{O}: \mathrm{Al}_{2} \mathrm{O}_{3}: \mathrm{SiO}_{2}$ ratios of $x: 1: y$, where $x=3-9$ and $y=$ 30 or $40^{a}$

\begin{tabular}{lllll} 
& \multicolumn{3}{c}{$\mathrm{SiO}_{2} / \mathrm{Al}_{2} \mathrm{O}_{3}$ ratio } & \\
\cline { 2 - 5 } $\mathrm{Na}_{2} \mathrm{O} / \mathrm{Al}_{2} \mathrm{O}_{3}$ ratio & 30 & 30 (with NaOH) & 40 & $40($ with NaOH) \\
\hline 3 & Amorphous & Amorphous & Amorphous & - \\
4 & Amorphous + trace ZSM-5 & Amorphous + trace ZSM-5 & Amorphous & Amorphous \\
5 & ZSM-5 & Mordenite + quartz & Amorphous + trace ZSM-5 & Amorphous + trace ZSM-5 \\
6 & ZSM-5 & - & Amorphous + trace ZSM-5 & Amorphous + trace ZSM-5 \\
7 & ZSM-5 + mordenite & Mordenite & Amorphous + trace ZSM-5 & ZSM-5 \\
8 & - & - & Quartz & ZSM-5 \\
9 & Mordenite & Mordenite & Mordenite + trace ZSM-5, quartz & Quartz
\end{tabular}

${ }^{a}$ Mechanochemically ground for $50 \mathrm{~min}$, then thermally treated at $180{ }^{\circ} \mathrm{C}$ for $48 \mathrm{~h}$, and then washed with water. The noted equivalent molar ratio amounts of $\mathrm{SiO}_{2}$ arises from both fumed $\mathrm{SiO}_{2}$ and $\mathrm{Na}_{2} \mathrm{SiO}_{3}, \mathrm{Al}_{2} \mathrm{O}_{3}$ equivalent arises from $\mathrm{Al}_{2}\left(\mathrm{SO}_{4}\right)_{3}$, and $\mathrm{Na}_{2} \mathrm{O}$ is from both $\mathrm{Na}_{2} \mathrm{SiO}_{3}$ and $\mathrm{NaOH}_{\text {if }}$ applicable).

strongly influenced by the free Na content as crystalline zeolites do not form at low free sodium levels (amorphous, disordered products), ZSM-5 forms at moderate sodium levels, and mordenite is favored at the highest sodium levels. The alkaline basicity in the mechanochemically ground precursor mixture, may lead to better aluminosilicate mixing that leads to crystallization of ZSM-5 using higher silica ratios and to mordenite at lower sodium levels. Several of these single-phase zeolite products were examined in more physical and compositional detail below.

As noted earlier, the $48 \mathrm{~h}$ heating at $180{ }^{\circ} \mathrm{C}$ of mechanochemically mixed reagents with equivalent $\mathrm{Na}_{2} \mathrm{O}: \mathrm{Al}_{2} \mathrm{O}_{3}$ $: \mathrm{SiO}_{2}$ ratios of $5: 1: 30$ leads to well-formed ZSM- 5 crystallites near $8 \mu \mathrm{m}$ in size (Fig. 2). Similarly well-formed aggregates of plate-like particles are observed for other single phase ZSM-5 products formed with $\mathrm{NaOH}$ and higher $\mathrm{Si} / \mathrm{Al}$ ratios $\left(\mathrm{Na}_{2}-\right.$ $\mathrm{O}: \mathrm{Al}_{2} \mathrm{O}_{3}: \mathrm{SiO}_{2}$ ratios of $7: 1: 40$ and $\left.8: 1: 40\right)$. The increased silica content and inclusion of $\mathrm{NaOH}$ here only modestly affect the ZSM-5 crystallite shape or size as the elongated faceted particle slabs in Fig. 5A and B are about 5-6 $\mu \mathrm{m}$ in their longest dimension. In contrast, two single-phase mordenite products are shown in Fig. 5C and D, one with added $\mathrm{NaOH}$ and one without, and they both form larger particles than ZSM-5, approaching $\sim 10 \mu \mathrm{m}$ along the longer slab direction. There are also indications of more uniform cube-like particle structures in the aggregates.

Beyond crystalline phase and physical morphology, it is useful to compare the relative crystallinity of the zeolite products as well as their surface areas and elemental compositions. Table 2 shows comparison data for several single-phase ZSM-5 and mordenite products identified by XRD analysis. The ZSM-5 and mordenite products all show appreciably high relative crystallinity at or above $85 \%$ and total accessible surface areas near $300 \mathrm{~m}^{2} \mathrm{~g}^{-1}$, both of which are compare favorably to commercial crystalline zeolite standards (Table 2). It is important to reinforce that as opposed to zeolite syntheses that uses organoamine structure directing agents, these mechanochemically-assisted solvent-free reactions produce crystalline zeolites that do not require a high-temperature $\left(\sim 500{ }^{\circ} \mathrm{C}\right)$ heating step to combust away embedded organic structure directing molecules and open up the internal zeolite channels and pores. The ICP-OES derived bulk compositions of the synthesized zeolites in Table 2 agree with typical Si/Al ratios for ZSM-5 and mordenite. The mordenite zeolite is the more Al-rich zeolite with $\mathrm{Si} / \mathrm{Al}$ ratios between $\sim 5-12$ while ZSM-5 materials have higher $\mathrm{Si} / \mathrm{Al}$ ratios near or above $\sim 15 .{ }^{5}$ The singlephase ZSM-5 products here show higher Si/Al values of 12-17 versus mordenite products in the 6-7 range. Both solvent-free ZSM-5 and mordenite products contain higher sodium content $(\mathrm{Na} / \mathrm{Al} \sim 2-6)$ than the ideal $\mathrm{Na} / \mathrm{Al} \approx 1$ values measured for commercial samples. The additional sodium
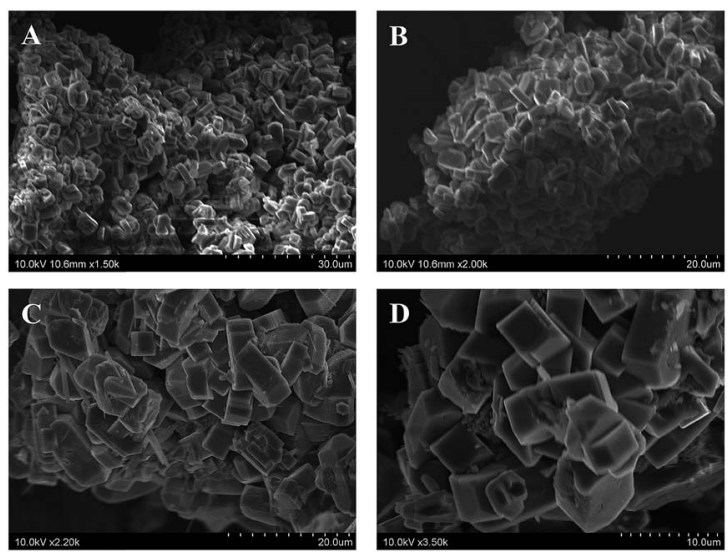

Fig. 5 SEM images of single-phase ZSM-5 (A and B) or mordenite (C and D) zeolites synthesized from reagent mixtures of $\mathrm{Na}_{2} \mathrm{SiO}_{3}$, $\mathrm{Al}_{2}\left(\mathrm{SO}_{4}\right)_{3}$, and $\mathrm{SiO}_{2}$ with and without $\mathrm{NaOH}$ addition (equivalent oxide amounts with $\mathrm{Na}_{2} \mathrm{O}: \mathrm{Al}_{2} \mathrm{O}_{3}: \mathrm{SiO}_{2}$ ratios of $x: 1: y$, see Table 1 entries) that were mechanochemically ground for $50 \mathrm{~min}$, then thermally treated at $180{ }^{\circ} \mathrm{C}$ for $48 \mathrm{~h}$, and then washed with water. Equivalent metal oxide ratios are: (A) $7: 1: 40$ (with $\mathrm{NaOH}$ ), (B) $8: 1: 40$ (with $\mathrm{NaOH}$ ), (C) $9: 1: 30$, and (D) $7: 1: 30$ (with $\mathrm{NaOH}$ ). 
may be a consequence of the concentrated solid-state growth process with some sodium serving a templating function as well as charge balance. For ZSM-5 samples, the addition of $\mathrm{NaOH}$ lead to larger sodium content in the final product. In the mixed phase and primarily amorphous isolated products, there is appears to be lower sodium incorporation, which may correlate with insufficient sodium content for effective zeolite templating (Table $\mathrm{S} 2 \dagger$ ).

\section{Evaluation of single-phase zeolites in biomass catalysis}

ZSM-5 zeolite catalysts have been used in biomass conversion of cellulose and glucose to useful chemicals such as hydroxymethylfurfural. ${ }^{49,54}$ To perform this catalysis, sodiumcontaining zeolites are cation-exchanged with protons to produce the acid form of a zeolite. While the as-synthesized zeolites from our solvent-free reactions yield products with high sodium content, after exchange with $\mathrm{NH}_{4} \mathrm{Cl}$ and heat treatment at $550{ }^{\circ} \mathrm{C}$, the resulting acid forms of ZSM-5 and mordenite retain their high $\sim 300 \mathrm{~m}^{2} \mathrm{~g}^{-1}$ surface areas and show low residual $\mathrm{Na}^{+}$content that is comparable to commercial zeolites treated in the same fashion (Table 3). A comparison of full nitrogen adsorption-desorption isotherms for several sodium and acid-exchange zeolites are shown in Fig. S5 $\uparrow$. While the overall curves are consistent with Type IV isotherms, the observed differences in their shapes can be attributed to different particle sizes and mesoporous volumes.

Several crystalline acid-exchanged ZSM-5 and mordenite $(\mathrm{H}-$ ZSM-5 and H-MOR) materials were tested for the catalytic performance in the biomass conversion of both ground glucose and cellulose. In the absence of a catalyst, very low biomass conversions (HMF yield) of 21\% (3\%) and 13\% (0.8\%) were found for glucose and cellulose, respectively. Ground cellulose was tested with commercial ZSM-5 and mordenite zeolite catalysts and both showed good 60-65\% total conversion with $\sim 28-35 \%$ HMF yields (Table 3). As expected, glucose conversion was higher than cellulose ( $\sim 80-90 \%$ with HMF yields near $40-$ $50 \%$ ). The acid-exchanged ZSM-5 and mordenite samples yield catalysis results generally about $\sim 10-15 \%$ lower than the commercial zeolite samples with total biomass conversion (HMF yield) $\sim 40-50 \%(\sim 20-30 \%)$ for cellulose and $\sim 70-80 \%$ $(\sim 30-40 \%)$ for glucose (Table 3 and Fig. 6$)$. The commercial zeolites have $\sim 40-80 \mathrm{~m}^{2} \mathrm{~g}^{-1}$ higher surface areas than the solvent-free template free zeolites, which will impact the number of surface catalytic sites. A qualitative examination of acid sites using pyridine surface reactions was performed on acid-exchanged commercial ZSM-5 and MOR versus several zeolites synthesized in this work. An IR analysis of pyridine exposed samples, shows qualitatively similar features consistent with a mixture of Lewis and Brønsted acid sites (Fig. S6 and $\mathrm{S} 7 \dagger) .{ }^{55,56}$ The small differences in catalytic activity could be

Table 2 Comparison of physical and chemical properties of selected single-phase zeolites

\begin{tabular}{|c|c|c|c|c|}
\hline Samples $^{a}$ & $\begin{array}{l}\text { Precursor, } \\
\mathrm{Na}_{2} \mathrm{O}: \mathrm{Al}_{2} \mathrm{O}_{3}: \mathrm{SiO}_{2}{ }^{b}\end{array}$ & $\begin{array}{l}\text { \% Relative } \\
\text { crystallinity }\end{array}$ & $\begin{array}{l}\text { Surface area } \\
\left(\mathrm{m}^{2} \mathrm{~g}^{-1}\right)\end{array}$ & $\begin{array}{l}\text { Product composition, } \\
\mathrm{Na}_{2} \mathrm{O}: \mathrm{Al}_{2} \mathrm{O}_{3}: \mathrm{SiO}_{2}{ }^{c}\end{array}$ \\
\hline ZSM-5-5 & $5: 1: 30$ & 95 & 324 & $2.2: 1.0: 26$ \\
\hline ZSM-5-6 & $6: 1: 30$ & 90 & 307 & $1.7: 1.0: 24$ \\
\hline ZSM-5-7 & $7: 1: 40$ (with $\mathrm{NaOH})$ & 94 & 318 & $5.8: 1.0: 33$ \\
\hline ZSM-5-8 & $8: 1: 40$ (with $\mathrm{NaOH})$ & 89 & 298 & $4.9: 1.0: 31$ \\
\hline MOR-7 & $7: 1: 30$ (with $\mathrm{NaOH})$ & 92 & 302 & $3.4: 1.0: 13$ \\
\hline MOR-9 & $9: 1: 30$ & 85 & 287 & $4.8: 1.0: 14$ \\
\hline Comm-Na-ZSM-5 & $\mathrm{n} / \mathrm{a}$ & 100 & 361 & $0.93: 1.0: 37$ \\
\hline Comm-Na-MOR & $\mathrm{n} / \mathrm{a}$ & 100 & 371 & $1.55: 1.0: 11$ \\
\hline
\end{tabular}

${ }^{a}$ Sample names are denoted as: zeolite phase $-\mathrm{Na}_{2} \mathrm{O} / \mathrm{Al}_{2} \mathrm{O}_{3}$ molar ratio in reaction. MOR = mordenite zeolite and "comm" refers to commercial sodium-containing zeolite samples. ${ }^{b}$ Equivalent metal oxide molar ratios in reactions are shown that arise from $\mathrm{Na}_{2} \mathrm{SiO}_{3}, \mathrm{Al}_{2}\left(\mathrm{SO}_{4}\right)_{3}$, and $\mathrm{SiO}_{2}$ with and without $\mathrm{NaOH}$ addition. Note that ideally molar equivalents of $\mathrm{Na}$ are sequestered as $\mathrm{Na}_{2} \mathrm{SO}_{4}$, so "free" Na for reaction is lower (e.g., $5: 1: 30$ would be $2: 1: 30$ for free Na available). ${ }^{c}$ Relative molar ratios are based on bulk product compositions measured by ICP-OES analysis.

Table 3 Comparison of relative composition and surface area for acid-exchanged single-phase zeolite samples and commercial ZSM-5 and mordenite materials

\begin{tabular}{lllll}
\hline Sample $^{a}$ & $\begin{array}{l}\text { ICP composition, } \\
\mathrm{Na}_{2} \mathrm{O}: \mathrm{Al}_{2} \mathrm{O}_{3}: \mathrm{SiO}_{2}{ }^{b}\end{array}$ & $\begin{array}{l}\text { Surface area } \\
\left(\mathrm{m}^{2} \mathrm{~g}^{-1}\right)\end{array}$ & $\begin{array}{l}\text { Biomass conversion } \\
(\%) \text { from glucose (cellulose) }\end{array}$ & $\begin{array}{l}\text { HMF yield (\%) } \\
\text { from glucose (cellulose) }\end{array}$ \\
\hline H-ZSM-5-5 & $0.27: 1.0: 33$ & 320 & $83(53)$ & $38(30)$ \\
H-ZSM-5-6 & $0.30: 1.0: 29$ & 311 & $72(49)$ & $42(24)$ \\
Comm H-ZSM-5 & $0.12: 1.0: 41$ & 355 & $82(65)$ & $48(35)$ \\
H-MOR-7 & $0.44: 1.0: 12$ & 296 & $76(43)$ & $31(27)$ \\
H-MOR-9 & $0.72: 1.0: 17$ & 283 & $78(40)$ & $36(22)$ \\
Comm H-MOR & $0.23: 1.0: 13$ & 373 & $88(60)$ & $37(28)$
\end{tabular}

${ }^{a}$ Sample names are denoted as: zeolite phase $-\mathrm{Na}_{2} \mathrm{O} / \mathrm{Al}_{2} \mathrm{O}_{3}$ molar ratio in reaction. MOR = mordenite zeolite and "comm" refers to commercial zeolite samples. ${ }^{b}$ Relative molar ratios are based on bulk product compositions as measured by ICP-OES analysis. 

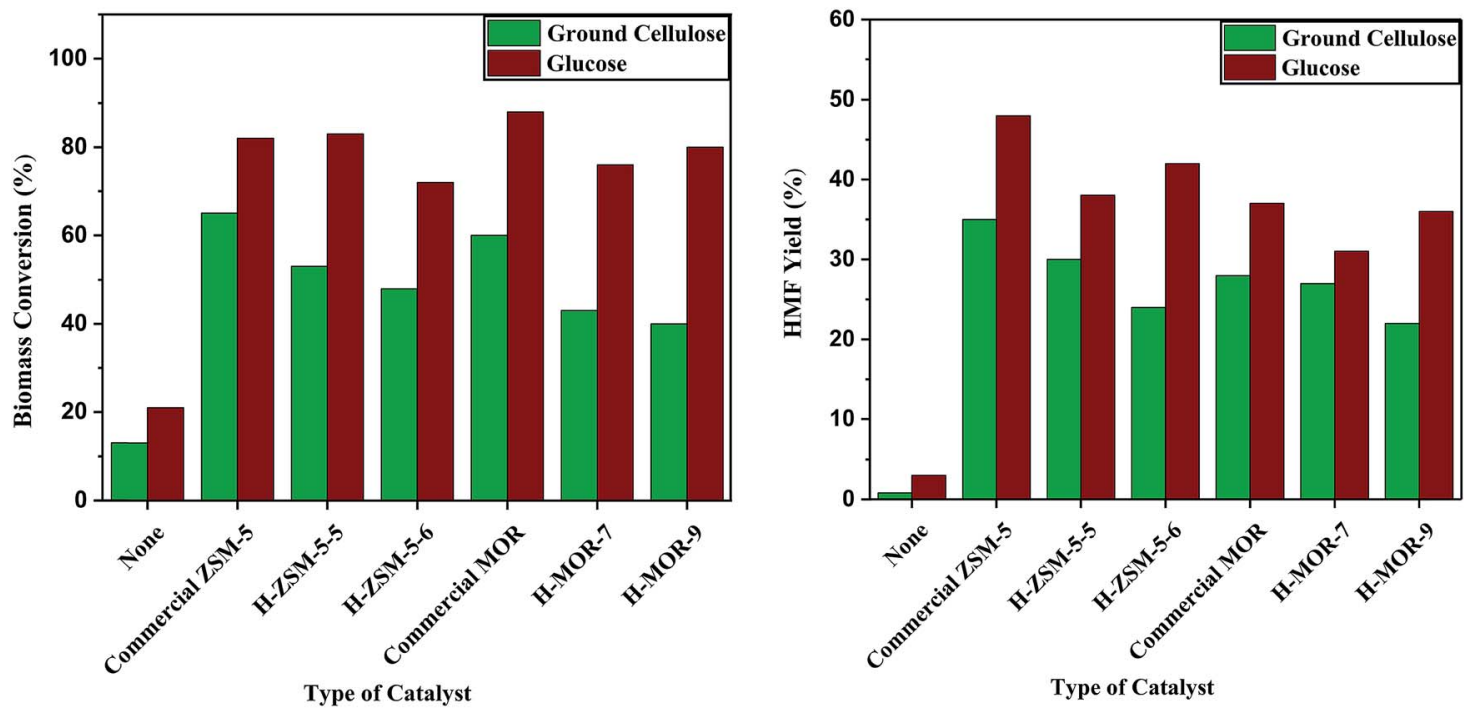

Fig. 6 Biomass conversion and HMF yield using synthesized single-phase acid-exchanged zeolite catalysts (ZSM-5 and mordenite). Left graph: overall biomass conversion of ground cellulose and glucose. Right graph: HMF yield from biomass conversion of ground cellulose and glucose. All zeolite catalysts examined here were used as their acid-exchanged forms.
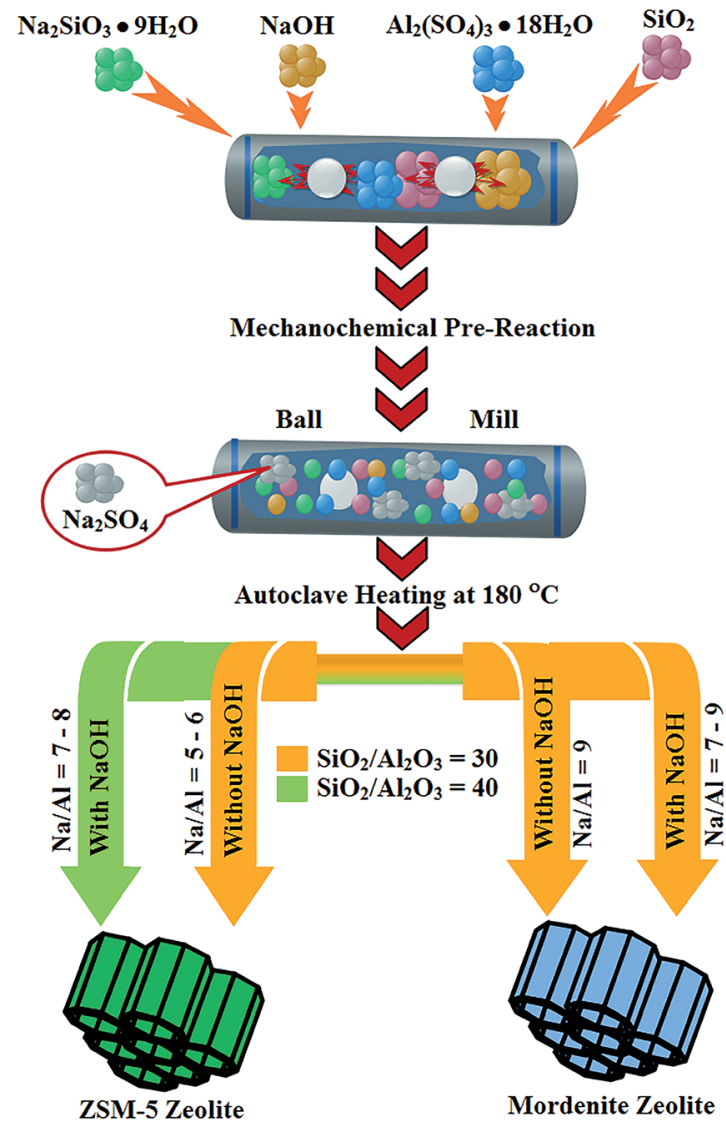

Scheme 1 Graphical summary of key reactions steps used and observed phase formation from mechanochemically-assisted solventfree and template-free zeolite synthesis without using any seeds.

attributed to differences in aluminum content, surface area, and surface acidity. These results show that the zeolites synthesized by a mechanochemically-assisted mixing with salt forming pre-reaction followed by solvent-free and template-free synthesis have accessible pore structures and show comparable catalytic activity to commercial zeolites.

\section{Conclusions}

A mechanochemical reagent grinding pre-reaction approach was used to form crystalline $\mathrm{Na}_{2} \mathrm{SO}_{4}$ and intimately mixed aluminosilicate precursors that thermally convert to crystalline ZSM-5 and mordenite zeolites at $180{ }^{\circ} \mathrm{C}$ under solvent-free conditions. As summarized in Scheme 1, higher silica and lower sodium content in the reagent mixture favor ZSM-5 products, while more $\mathrm{Na}$ and $\mathrm{Al}$ rich reagent mixtures favor mordenite, which parallels observations from conventional hydrothermal reactions. The zeolite materials were successfully produced in the absence of an organic structure directing template, zeolite seeds, or added solvent. A 50 minute high energy ball milling step provides sufficient mechanochemical reaction to facilitate successful single-phase zeolite synthesis at moderate temperatures. A moderate level of free sodium content in the mixture is important for zeolite crystallization, indicating that sodium cations play an important structure directing agent role in addition to providing charge compensation for $\mathrm{Al}^{3+}$ in the silicate network. All single-phase zeolites have well-formed faceted micrometer-sized particle shapes with high surface areas near $300 \mathrm{~m}^{2} \mathrm{~g}^{-1}$ directly from the solvent-free and template-free synthesis. The synthesized zeolite materials were tested for cellulose and glucose biomass conversion to HMF and showed catalytic activity comparable to commercial ZSM-5 and mordenite zeolites.

\section{Conflicts of interest}

The authors declare no conflicts of interest. 


\section{Acknowledgements}

The University of Iowa's Department of Chemistry and Graduate College are acknowledged for support (MHN). This project was also partially funded by a U.S. National Science Foundation grant (CHE-1538847, SCL).

\section{References}

1 S. Mintova, J.-P. Gilson and V. Valtchev, Advances in nanosized zeolites, Nanoscale, 2013, 5, 6693-6703.

2 L. Tosheva and V. P. Valtchev, Nanozeolites: Synthesis, crystallization mechanism, and applications, Chem. Mater., 2005, 17, 2494-2513.

3 S. E. Lehman and S. C. Larsen, Zeolite and mesoporous silica nanomaterials: greener syntheses, environmental applications and biological toxicity, Environ. Sci.: Nano, 2014, 1, 200.

4 E. Taarning, C. M. Osmundsen, X. Yang, B. Voss, S. I. Andersen and C. H. Christensen, Zeolite-catalyzed biomass conversion to fuels and chemicals, Energy Environ. Sci., 2011, 4, 793.

5 B. K. Singh, Y. Kim, S. Bin Baek, A. Meena, S. Sultan, J. H. Kwak and K. S. Kim, Template free facile synthesis of mesoporous mordenite for bulky molecular catalytic reactions, J. Ind. Eng. Chem., 2018, 57, 363-369.

6 J. C. Groen, T. Sano, J. A. Moulijn and J. Pérez-Ramírez, Alkaline-mediated mesoporous mordenite zeolites for acidcatalyzed conversions, J. Catal., 2007, 251, 21-27.

7 R. Karimi, B. Bayati, N. Charchi Aghdam, M. Ejtemaee and A. A. Babaluo, Studies of the effect of synthesis parameters on ZSM-5 nanocrystalline material during templatehydrothermal synthesis in the presence of chelating agent, Powder Technol., 2012, 229, 229-236.

8 W. Song, R. E. Justice, C. A. Jones, V. H. Grassian and S. C. Larsen, Synthesis, characterization, and adsorption properties of nanocrystalline ZSM-5, Langmuir, 2004, 20, 8301-8306.

9 A. Petushkov, S. Yoon and S. C. Larsen, Synthesis of hierarchical nanocrystalline ZSM-5 with controlled particle size and mesoporosity, Microporous Mesoporous Mater., 2011, 137, 92-100.

10 W. Song, V. H. Grassian and S. C. Larsen, High yield method for nanocrystalline zeolite synthesis, Chem. Commun., 2005, 23, 2951-2953.

11 C. I. Round, C. D. Williams, K. Latham and C. V. A. Duke, NiZSM-5 and Cu-ZSM-5 synthesized directly from aqueous fluoride gels, Chem. Mater., 2001, 13, 468-472.

12 R. J. White, A. Fischer, C. Goebel and A. Thomas, A sustainable template for mesoporous zeolite synthesis, $J$. Am. Chem. Soc., 2014, 136, 2715-2718.

13 Y. Wang, Q. Wu, X. Meng and F. S. Xiao, Insights into the Organotemplate-Free Synthesis of Zeolite Catalysts, Engineering, 2017, 3, 567-574.

$14 \mathrm{H}$. Kalipcilar and A. Culfaz, Influence of nature of silica source on template-free synthesis of ZSM-5, Cryst. Res. Technol., 2001, 36, 1197-1207.
15 H. Wang, B. A. Holmberg and Y. Yan, Synthesis of templatefree zeolite nanocrystals by using in situ thermoreversible polymer hydrogels, J. Am. Chem. Soc., 2003, 125, 9928-9929.

16 Y. Pan, M. Ju, J. Yao, L. Zhang and N. Xu, Preparation of uniform nano-sized zeolite A crystals in microstructured reactors using manipulated organic template-free synthesis solutions, Chem. Commun., 2009, 46, 7233-7235.

17 T. Tang, L. Zhang, H. Dong, Z. Fang, W. Fu, Q. Yu and T. Tang, Organic template-free synthesis of zeolite $\mathrm{Y}$ nanoparticle assemblies and their application in the catalysis of the Ritter reaction, RSC Adv., 2017, 7, 7711-7717.

18 H. M. Aly, M. E. Moustafa and E. A. Abdelrahman, Synthesis of mordenite zeolite in absence of organic template, Adv. Powder Technol., 2012, 23, 757-760.

19 Z. Chen, S. Li and Y. Yan, Synthesis of template-free zeolite nanocrystals by reverse microemulsion-microwave method, Chem. Mater., 2005, 17, 2262-2266.

20 H. Zhang, H. Zhang, P. Wang, Y. Zhao, Z. Shi, Y. Zhang and Y. Tang, Organic template-free synthesis of zeolite mordenite nanocrystals through exotic seed-assisted conversion, RSC Adv., 2016, 6, 47623-47631.

21 V. P. Shiralkar and A. Clearfield, Synthesis of the molecular sieve ZSM-5 without the aid of templates, Zeolites, 1989, 9, 363-370.

22 Y. Cheng, R. H. Liao, J. S. Li, X. Y. Sun and L. J. Wang, Synthesis research of nanosized ZSM-5 zeolites in the absence of organic template, J. Mater. Process. Technol., 2008, 206, 445-452.

23 L. Zhang, S. Liu, S. Xie and L. Xu, Organic template-free synthesis of ZSM-5/ZSM-11 co-crystalline zeolite, Microporous Mesoporous Mater., 2012, 147, 117-126.

24 M. H. Nada and S. C. Larsen, Insight into seed-assisted template free synthesis of ZSM-5 zeolites, Microporous Mesoporous Mater., 2017, 239, 444-452.

25 Q. Yu, Q. Zhang, J. Liu, C. Li and Q. Cui, Inductive effect of various seeds on the organic template-free synthesis of zeolite ZSM-5, CrystEngComm, 2013, 15, 7680.

26 K. Itabashi, Y. Kamimura, K. Iyoki, A. Shimojima and T. Okubo, A working hypothesis for broadening framework types of zeolites in seed-assisted synthesis without organic structure-directing agent, J. Am. Chem. Soc., 2012, 134, 11542-11549.

27 N. Ren, J. Bronić, T. A. Jelić, A. Palčić and B. Subotić, Seedinduced, structure directing agent-free crystallization of sub-micrometer zeolite ZSM-5: A population balance analysis, Cryst. Growth Des., 2012, 12, 1736-1745.

28 G. Majano, A. Darwiche, S. Mintova and V. Valtchev, Seedinduced crystallization of nanosized Na-ZSM-5 crystals, Ind. Eng. Chem. Res., 2009, 48, 7084-7091.

29 Q. Yu, X. Meng, J. Liu, C. Li and Q. Cui, A fast organic template-free, ZSM-11 seed-assisted synthesis of ZSM-5 with good performance in methanol-to-olefin, Microporous Mesoporous Mater., 2013, 181, 192-200.

30 M. Razavian, S. Fatemi and M. Komasi, Seed-assisted OSDAfree synthesis of ZSM-5 zeolite and its application in dehydrogenation of propane, Mater. Res. Bull., 2015, 65, 253-259. 
31 T. D. Todorova and Y. A. Kalvachev, Seed-mediated approach to size-controlled synthesis of a mordenite type zeolite from organic template free initial gel, Bulg. Chem. Commun., 2015, 47, 409-416.

32 M. H. Nada, E. G. Gillan and S. C. Larsen, Mechanochemical reaction pathways in solvent-free synthesis of ZSM-5, Microporous Mesoporous Mater., 2019, 276, 23-28.

33 Q. Wu, X. Liu, L. Zhu, L. Ding, P. Gao, X. Wang, S. Pan, C. Bian, X. Meng, J. Xu, F. Deng, S. Maurer, U. Müller and F. S. Xiao, Solvent-free synthesis of zeolites from anhydrous starting raw solids, J. Am. Chem. Soc., 2015, 137, 1052-1055.

34 Q. Wu, X. Meng, X. Gao and F. S. Xiao, Solvent-Free Synthesis of Zeolites: Mechanism and Utility, Acc. Chem. Res., 2018, 51, 1396-1403.

35 R. E. Morris and S. L. James, Solventless synthesis of zeolites, Angew. Chem., Int. Ed., 2013, 52, 2163-2165.

36 W. Luo, X. Yang, Z. Wang, W. Huang, J. Chen, W. Jiang, L. Wang, X. Cheng, Y. Deng and D. Zhao, Synthesis of ZSM-5 aggregates made of zeolite nanocrystals through a simple solvent-free method, Microporous Mesoporous Mater., 2017, 243, 112-118.

37 Z. Liu, D. Wu, S. Ren, X. Chen, M. Qiu, G. Liu, G. Zeng and Y. Sun, Facile one-pot solvent-free synthesis of hierarchical ZSM-5 for methanol to gasoline conversion, RSC Adv., 2016, 6, 15816-15820.

38 T. Wakihara, R. Ichikawa, J. Tatami, A. Endo, K. Yoshida, Y. Sasaki, K. Komeya and T. Meguro, Bead-milling and postmilling recrystallization: an organic template-free methodology for the production of nano-zeolites, Cryst. Growth Des., 2011, 11, 955-958.

39 T. Wakihara, A. Ihara, S. Inagaki, J. Tatami, K. Sato, K. Komeya, T. Meguro, Y. Kubota and A. Nakahira, Topdown tuning of nanosized ZSM-5 zeolite catalyst by bead milling and recrystallization, Cryst. Growth Des., 2011, 11, 5153-5158.

40 Q. Wu, X. Wang, G. Qi, Q. Guo, S. Pan, X. Meng, J. Xu, F. Deng, F. Fan, Z. Feng, C. Li, S. Maurer, U. Müller and F. S. Xiao, Sustainable synthesis of zeolites without addition of both organotemplates and solvents, J. Am. Chem. Soc., 2014, 136, 4019-4025.

41 L. Ren, Q. Wu, C. Yang, L. Zhu, C. Li and P. Zhang, Solventfree Synthesis of Zeolites from Solid Raw, J. Am. Chem. Soc., 2012, 134, 15173-15176.

42 W. Gao, C. C. Amoo, G. Zhang, M. Javed, B. Mazonde, C. Lu, R. Yang, C. Xing and N. Tsubaki, Insight into solvent-free synthesis of MOR zeolite and its laboratory scale production, Microporous Mesoporous Mater., 2019, 280, 187-194.

43 M. H. Nada, S. C. Larsen and E. G. Gillan, Solvent-free synthesis of crystalline ZSM-5 zeolite: Investigation of mechanochemical pre-reaction impact on growth of thermally stable zeolite structures, Solid State Sci., 2019, 94, 15-22.
44 S. L. James, C. J. Adams, C. Bolm, D. Braga, P. Collier, T. Friščić, F. Grepioni, K. D. M. Harris, G. Hyett, W. Jones, A. Krebs, J. Mack, L. Maini, A. G. Orpen, I. P. Parkin, W. C. Shearouse, J. W. Steed and D. C. Waddell, Mechanochemistry: opportunities for new and cleaner synthesis, Chem. Soc. Rev., 2012, 41, 413-447.

45 A. Karmakar, M. S. Dodd, X. Zhang, M. S. Oakley, M. Klobukowski and V. K. Michaelis, Mechanochemical Synthesis of 3D and 0D Cesium Lead Mixed Halide Perovskite Solid Solutions, Chem. Commun., 2019, 55, 5079-5082.

46 A. O. Atoyebi and C. Brückner, Observations on the Mechanochemical Insertion of Zinc(II), Copper(II), Magnesium(II), and Select Other Metal(II) Ions into Porphyrins, Inorg. Chem., 2019, 58, 9631-9642.

47 P. A. Julien, K. Užarević, A. D. Katsenis, S. A. J. Kimber, T. Wang, O. K. Farha, Y. Zhang, J. Casaban, L. S. Germann, M. Etter, R. E. Dinnebier, S. L. James, I. Halasz and T. Friščić, In Situ Monitoring and Mechanism of the Mechanochemical Formation of a Microporous MOF-74 Framework, J. Am. Chem. Soc., 2016, 138, 2929-2932.

48 T. Friščić, I. Halasz, P. J. Beldon, A. M. Belenguer, F. Adams, S. A. J. Kimber, V. Honkimäki and R. E. Dinnebier, Real-time and in situ monitoring of mechanochemical milling reactions, Nat. Chem., 2013, 5, 66-73.

49 K. Y. Nandiwale, N. D. Galande, P. Thakur, S. D. Sawant, V. P. Zambre and V. V. Bokade, One-pot synthesis of 5hydroxymethylfurfural by cellulose hydrolysis over highly active bimodal micro/mesoporous H-ZSM-5 catalyst, ACS Sustainable Chem. Eng., 2014, 2, 1928-1932.

50 D. P. Chen, J. Fu and S. E. Skrabalak, Towards Shape Control of Metal Oxide Nanocrystals in Confined Molten Media, ChemNanoMat, 2015, 1, 18-26.

51 E. S. Toberer, J. C. Weaver, K. Ramesha and R. Seshadri, Macroporous monoliths of functional perovskite materials through assisted metathesis, Chem. Mater., 2004, 16, 21942200.

52 E. G. Gillan and R. B. Kaner, Synthesis of refractory ceramics via rapid metathesis reactions between solid-state precursors, Chem. Mater., 1996, 8, 333-343.

53 N. Y. Kang, B. S. Song, C. W. Lee, W. C. Choi, K. B. Yoon and Y. K. Park, The effect of $\mathrm{Na}_{2} \mathrm{SO}_{4}$ salt on the synthesis of ZSM5 by template free crystallization method, Microporous Mesoporous Mater., 2009, 118, 361-372.

54 E. Taarning, C. M. Osmundsen, X. Yang, B. Voss, S. I. Andersen and C. H. Christensen, Zeolite-catalyzed biomass conversion to fuels and chemicals, Energy Environ. Sci., 2011, 4, 793-804.

55 J. Connerton, R. W. Joyner and M. B. Padley, Characterisation of the acidity of well defined Cu-ZSM-5 catalysts using pyridine as a probe molecule, J. Chem. Soc., Faraday Trans., 1995, 91, 1841-1844.

56 T. Barzetti, E. Selli, D. Moscotti and L. Forni, Pyridine and ammonia as probes for FTIR analysis of solid acid catalysts, J. Chem. Soc., Faraday Trans., 1996, 92, 1401-1407. 